\title{
Segregation, fertility, and son preference: the case of the Roma in Serbia
}

\author{
Marianna Battaglia $^{1 \star}$, Bastien Chabé-Ferret ${ }^{2,3}$ (D) and Lara Lebedinski ${ }^{4}$ \\ ${ }^{1}$ Department of Economics (FAE-Fundamentos del Análisis Económico), University of Alicante, Campus \\ de San Vicente, 03080 Alicante, Spain, ${ }^{2}$ LISER, 11 Porte des Sciences, L-4366 Esch, Belval, Luxembourg, \\ ${ }^{3}$ IZA, Bonn, Germany and ${ }^{4}$ Institute of Economic Sciences, Zmaj Jovina 12, 11000 Belgrade, Serbia \\ ${ }^{*}$ Corresponding author. E-mail: mbattaglia@ua.es
}

(Received 9 May 2019; revised 9 April 2020; accepted 10 April 2020)

\begin{abstract}
We study the link between residential segregation and fertility for the socially excluded and marginalized Roma ethnic minority. Using original survey data we collected in Serbia, we investigate whether fertility differs between ethnically homogeneous and mixed neighborhoods. Our results show that Roma in less-segregated areas tend to have significantly fewer children (around 0.8). Most of the difference arises from Roma in less-segregated areas waiting substantially more after having a boy than their counterparts in more-segregated areas. We exploit variation in the share of Serbian sounding first names to provide evidence that a mechanism at play is a shift in preferences toward lower fertility and sons rather than daughters induced by a higher exposure to the Serbian majority culture.
\end{abstract}

Key words: Culture; ethnic minority; fertility; residential segregation

JEL classification: J13; J15; R23; Z10

\section{Introduction}

The Roma population, like many other marginalized minority groups, is characterized by high levels of fertility and severe residential segregation. Yet, both the direction of causality and the mechanism responsible for this correlation remain unclear. Is it that minorities more inclined toward a higher fertility tend to crowd out other types from their neighborhoods and become segregated as a result or that groups that are initially isolated tend to be biased toward larger families? Alternatively, it could be that a third factor causes both segregation and high fertility. ${ }^{1}$

\footnotetext{
${ }^{1}$ Minorities speaking a language that is very distant from that of the majority for instance could tend to be more isolated and disadvantaged on the labor market, which decreases the opportunity cost of having children.

(C) The Author(s), 2021. Published by Cambridge University Press on behalf of Université catholique de Louvain. This is an Open Access article, distributed under the terms of the Creative Commons Attribution licence (http://creative commons.org/licenses/by/4.0/), which permits unrestricted re-use, distribution, and reproduction in any medium, provided the original work is properly cited.
} 
The aim of this paper is to use variation in the severity of residential segregation of Roma settlements to shed some light on the association between segregation and fertility. ${ }^{2}$ A further goal is to investigate the different pathways that can link segregation to fertility. Our analysis has two important limitations that the reader should keep in mind. First, we are not able to formally infer causal links as the heterogeneity in residential segregation does not stem from quasi-experimental variation. Second, the data we exploit suffer from selection issues that do not guarantee its representativity of the Roma population. ${ }^{3}$

Despite those limitations, we believe that providing answers to these questions, even if only suggestive, are of primary importance. Indeed it improves our understanding of whether policies favoring social diversity may be helpful to reduce what some consider as a fertility burden, which prevents parents from investing in the quality of their children. ${ }^{4}$ Understanding better the link between segregation and fertility is also crucial as policies favoring social diversity may target access to different amenities, such as housing, schools, or jobs, and some may prove more efficient than others.

In particular, we have in mind five mechanisms through which segregation may affect fertility: (i) people in less-segregated areas may have access to better employment possibilities and therefore have a higher opportunity cost of time [Doepke (2015)]; (ii) people in less-segregated areas may face higher returns to education and therefore prefer to invest in quality rather than quantity of children [Galor (2012)]; (iii) people in segregated areas may be closer to the grandparents' location and raising children would consequently be less costly [Compton and Pollak (2014)]; (iv) the cost of space could be lower in segregated areas as fewer people desire to live there [Boustan (2012); Boustan and Margo (2013)], thus facilitating a higher fertility [Simon and Tamura (2009)]; and (v) people in less-segregated areas may be more exposed to the Serbian majority culture and its low-fertility norm [Fernández and Fogli $(2006,2009)]$.

We investigate further the idea of cultural transmission from the majority group by exploring the timing of births and in particular how timing patterns depend on the gender of the last born child. Indeed, longer intervals after a son vs. a daughter signals a preference for boys, which is widely recognized as a culturally transmitted trait and is particularly prevalent in Serbia and surrounding countries [Abramishvili et al. (2019)]. In addition to pointing at the cultural pathway as a crucial mechanism of fertility change, documenting a preference for boys also raises other policy relevant issues, such as the promotion of gender equity.

For the purpose of our analysis, we use primary data collected through an extensive survey conducted in Belgrade, Serbia. In the Fall of 2010, we interviewed 300 Roma households in 13 different settlements of the city. These households were randomly selected among households with at least one child attending primary schools involved in a remedial education program introduced in Serbia in 2009. ${ }^{5}$ Our study

\footnotetext{
${ }^{2}$ Settlements and neighborhoods are used interchangeably, except when further defined.

${ }^{3}$ Section 2.2 discusses in detail the different selection issues and how we try to mitigate them.

${ }^{4}$ There exists an important literature showing that the decline in fertility known as the demographic transition is prior to the economic take-off. See for instance the seminal contributions by Galor and Weil $(1999,2000)$ and subsequent articles building on the issue such as Kalemli-Ozcan (2002), Li and Zhang (2007), Klemp and Weisdorf (2019), and Cervellati and Sunde (2015).

${ }^{5}$ Data were collected to examine the impact of a remedial education program targeting primary school-age Roma children on parental expectations. More details can be found in Battaglia and Lebedinski $(2015,2017)$.
} 
de facto focuses on the intensive margin of fertility (or fertility of mothers). We discuss this point in subsection 2.2.

We first document that there exists heterogeneity within the Roma community in Serbia in terms of both segregation and fertility. Residential segregation is measured as the proportion of Roma living in a settlement and we distinguish between only Roma, mostly, or few Roma. In our sample, $27 \%$ of the households live in only Roma neighborhoods, $62 \%$ in mostly Roma, and 9\% in few Roma settlements. We establish that households in few Roma settlements tend to have fewer children than those in only Roma (0.8 children). Incorporating controls for the different mechanisms previously described, either in isolation or altogether, can only partially account for the gap.

We then investigate whether this fertility gap is accompanied by a preference toward sons rather than daughters. Using a proportional hazard duration model, we show that the difference in fertility is not accompanied by any sizeable difference in age at first birth or spacing after having a girl. However, we document that parents in few Roma settlements wait significantly longer after having a boy than similar parents in more-segregated settlements. Looking at a sample of non-Roma Serbs from the UNICEF Multiple Indicator Cluster Survey [MICS (2010)], we check that this pattern of longer inter-birth spells after having a boy also holds among Serbs, making the case for cultural porosity between few Roma settlements and the Serbian majority. We moreover document consistent results when investigating the sex ratio at last birth, another indicator of son preference, particularly relevant in the absence of sex-selective abortion.

Our contribution is threefold. First, we describe substantial spatial disparities in fertility behavior within an ethnic minority, in our case the Roma community. An extensive literature documents fertility gaps across religious and ethnic groups in many different contexts. Manski and Mayshar (2003) and Berman (2000) for instance document substantial fertility gaps across different groups in Israel. Poston et al. (2006) offer the same kind of analysis applied to minority groups in China. Adsera (2006) look at different religious affiliations in Spain, while Coleman and Dubuc (2010) document them for minority ethnic groups in the UK. Directly connected to our study, Sedlecky and Rašević (2015) quantify the fertility differences between Roma living in settlements and the Serbian majority using the UNICEF MICS as well as a qualitative survey. They document large differences in fertility, driven by early marriages and first births, as well as very low usage of modern contraception. The qualitative survey highlights the importance of traditional views on marriage and contraception, poor employment perspectives, and low-perceived returns to education.

However, much fewer studies point at the heterogeneity within those ethnic groups, as in the present paper. The heterogeneity within the Roma community is a crucial point as it can help us understand how social change happens and in particular whether diffusion of norms is an important factor. There exist some sociological and anthropological accounts for Hungary. For instance, Spéder and Kamarás (2008) draw a link between a study by Hablicsek (2008), which documents regional variation in the fertility patterns of Roma people in Hungary, and anthropological work by Durst (2002) who points at the "ghettoization" of the Roma population, to explain the increased fertility in some deprived villages of Northern Hungary. Furthermore, Janky (2006) also documents geographic variation within the Roma population in Hungary and links it mainly to differences in the level of integration into the education system and the labor market. Interestingly enough, he also mentions a sharp distinction between the more integrated but also more recently 
settled community affiliated to the Beás culture and dialect, as opposed to those identifying to the Olah culture. However, we are not aware of any study systematically correlating fertility differences within the Roma community with residential segregation using econometric techniques.

Our second contribution is to document that the lower fertility in less-segregated areas is accompanied by a higher preference for sons over daughters. This is of importance in its own right, as son preference has drastic consequences on gender differences in health, education, and labor outcomes. ${ }^{6}$ Once in utero sex-detection technologies become available, son preference may also translate into a skewed sex ratio at birth, the consequences of which are a concern for many Asian countries. ${ }^{7}$ However, this is also informative so as to how behavioral change happens. Indeed, low fertility and son preference are also very prevalent in the ethnic Serbian population. Our findings therefore point at a process of cultural diffusion from the majority group to the less-segregated minority populations, which is an important point for policy makers to keep in mind. Anukriti (2018) evaluates the impact of one such policy in India, called Devi Rupak, which seeks to lower fertility and the sex ratio, and finds that financial incentives have little effect, therefore suggesting a substantial role of cultural persistence.

Several contributions in economics have now documented the importance of cultural norms, in addition to purely economic drivers, in the transition to a low-fertility regime. ${ }^{8}$ This fairly recent interest of economists for cultural norms of fertility prolongs a long-standing debate in demography and sociology, regarding not only the transition from high to low fertility, but also fertility differences across ethnic and religious groups. The sociological literature refers to three hypotheses: (i) the characteristics hypothesis (or in demography, the structuralist view), which states that, once accounted for differences in socio-demographic characteristics, fertility differences should disappear, (ii) the cultural hypothesis, according to which fertility differences persist due to the slow process of acculturation of minorities to the majority culture (known as the diffusionist view in demography), and (iii) the minority status hypothesis, which posits that minority group membership may have an independent effect on fertility, either positive or negative due to the desire and perceived possibility of upward social mobility.

These hypotheses have been revisited by the economics literature. The seminal contributions by Fernández and Fogli (2006, 2009) bring to light the correlation between the behavior of second-generation migrant women to the USA and the total

\footnotetext{
${ }^{6}$ See Altindag (2016) and Jayachandran and Pande (2017) for evidence in the context of Turkey and India.

${ }^{7}$ Anukriti et al. (2018) find that the detrimental effects of son preference on daughters' outcomes are somewhat mitigated by the introduction of ultrasound technology allowing sex-selective abortions, as they decrease the number of unwanted births. Hesketh and Xing (2006) discuss the possible consequences of skewed sex ratios, gender imbalances, and missing women on the marginalization of single men, the prevalence of antisocial behavior, violence, and sex trafficking.

${ }^{8}$ de la Croix and Perrin (2018) analyze fertility and schooling data for 19th century France and find that a purely economic model may explain $38 \%$ of the cross-county variation in fertility and more than $75 \%$ of the variation in schooling decisions. Residuals from the model correlate well with cultural proxies, such as family structure and linguistic barriers. Daudin et al. (2018) use similar data to highlight the role of internal migration from and to Paris as a vector for cultural diffusion. Spolaore and Wacziarg (2016) document that cultural distance (as measured by genetic and linguistic distance) was a key driver to the diffusion of low fertility norms across European populations prior and during the industrial revolution.
} 
fertility rate in their country of origin to give strong empirical support to the existence of the cultural channel. ${ }^{9}$ Chabé-Ferret (2013) shows that the characteristics hypothesis does not allow one to explain fully the fertility gap between non-Hispanic Whites and African-Americans in the USA and give some evidence pointing at the importance of the cultural channel.

Goldscheider and Uhlenberg (1969) were the first to propose the concept of minority status hypothesis, which gave rise to a substantial literature that tried to prove or disprove them. Forste and Tienda (1996) provide a critical review of 10 of the most influential contributions in that "first generation" of sociological studies of fertility differential. In the economics literature, Chabé-Ferret and Melindi Ghidi (2013) build a theoretical model that suggests economic uncertainty as the mechanism underlying the minority status hypothesis. They find that middle-sized minority groups should tend to have a higher fertility than comparable natives while small minorities should tend to have fewer children.

Our work is also related to the literature on residential segregation and neighborhood effects that studies the relevance of neighborhoods and one's peers in influencing socioeconomic outcomes. ${ }^{10}$ For instance, segregation of African-Americans has been identified as one of the reasons for the persistence of inner city poverty in the USA [Cutler and Glaeser (1997)]. Moreover, the neighborhood where one lives can clearly affect one's labor market [Clark and Drinkwater (2002); Edin et al. (2003); Bayer et al. (2008); Boeri et al. (2015)] and educational outcomes [Card and Rothstein (2007)]. The ethnic composition of a municipality can also be important for the quality of local public goods such as schools [Alesina et al. (1999); La Ferrara and Mele (2006)]. Manley et al. (2011) suggest that the evidence base for social mixing is far from robust. Our setting allows us to better isolate the link between segregation and fertility for a minority group, given that we can observe different levels of segregation for the same ethnic minority, which is the largest in Europe.

Our third contribution is to provide primary data in a context where data are scarce, the Roma community, an understudied ethnic minority that has endured a history of discrimination and marginalization. We collected data at a very detailed level of geographical disaggregation-the street, which, despite several limitations discussed in section 2, represents an important contribution in and of itself. We complement work that has been carried out on Roma communities in other countries. Aisa et al. (2017) for instance examine the fertility patterns of Roma in Spain and find that family businesses play an important role. In the presence of a family business, parents exert their authority to influence the fertility decision of their adult children in the view of maximizing future labor resources at the disposal of the family. While the paper makes an important contribution, we believe that this finding is not relevant for our context where families are mostly nuclear. Family businesses involving extended family members and vertical hierarchy across generations are not common among Roma in Serbia. Kertesi and Kézdi (2013) document the extent of segregation in the primary school system in Hungary, while Kertesi and Kézdi (2011a, 2011b) and Hajdu et al. (2017) explore the consequences in terms of Roma/ non-Roma gaps, respectively, in test scores, employment, and health outcomes. Rauh

\footnotetext{
${ }^{9}$ See Blau et al. (2013), Stichnoth and Yeter (2016), and Chabé-Ferret (2019) for further exploration on the cultural channel at play in fertility behavior.

${ }^{10}$ For an excellent review of the literature on neighborhood effects, see Durlauf (2004) and Blume and Durlauf (2006).
} 
(2018) also documents large Roma/non-Roma gaps for Romania, in terms of school attendance, educational attainment, housing conditions, and employment, as well as in the extent of the gender gap in those outcomes. Aisa and Larramona (2014) and Aisa et al. (2016) uncover similar patterns in terms of labor market outcomes and self-reported health in Spain.

The rest of the paper is organized as follows. Section 2 describes the way the survey has been designed and the data collected. It provides some descriptive statistics. Section 3 presents the estimation strategy and the results. Section 4 discusses findings and concludes.

\section{Data and descriptive statistics}

\subsection{Official data on Roma}

Roma are the largest ethnic minority in Europe. In all the countries where they live, they experience severe social exclusion and poverty. They mainly perform low-skilled jobs, live in segregated areas of the main cities, and do not participate in the political and cultural life [Open Society Institute (2007)]. Their living conditions are often so different from those of the majority population that it is difficult to find official data documenting their situation. For most Central and Eastern European countries where the majority of the Roma population lives, official data on them are scarce and inaccurate. The 2011 Serbian Census counts 147,604 Roma, corresponding to $2.05 \%$ of the total Serbian population, while the Open Society Institute (2007) estimates a number between 350,000 and 500,000, approximately $6 \%$ of the overall population. In Belgrade, the 2011 Census records 27,325 Roma (1.65\% of the population) and the Open Society Institute (2007)'s numbers are three times higher: they are roughly 80,000 (5\%).

The UNICEF MICS from 2010 and the Living Standard Measurement Survey (LSMS) from 2007 are valuable sources of information on the living conditions of the Roma population in Serbia. However, the MICS does not report information on where the households interviewed live and therefore cannot be used in our study. Furthermore, the LSMS only interviewed a boosted sample of internally displaced people, making it a very selected sample.

We make use of these sources in order to compare the characteristics of the Roma and non-Roma populations. As reported in Table A in the Appendix, the average Roma household is composed of 5.6 members vs. a national average of 3.5. The average number of children aged 18 or below is 2.4 per Roma household, while the population average is only 0.86 . Almost half of the Roma population (43\%) is below 18 years old and the average age is 25 , whereas the national average is 35 . Half of the Roma households are poor: their average consumption is below the absolute poverty line. ${ }^{11}$ While male employment rates are comparable to those of the majority population $(56 \%)$, female employment remains very low with only one woman out of 10 working vs. a national average of $40 \%$. Only $89 \%$ of children from Roma settlements aged 6-15 attend school and among the adults, $29 \%$ have not finished primary school. ${ }^{12}$ Conversely, 99\% of non-Roma aged 6-15 are enrolled in school and only $4 \%$ of adults have not completed primary school.

\footnotetext{
${ }^{11}$ The percentage of the extremely poor among the Roma interviewed in LSMS is $11.9 \%$. Those who are considered extremely poor are those who cannot satisfy even their basic needs for food.

${ }^{12}$ In Serbia, school is compulsory until the age of 15 and primary school lasts 8 years. Children enroll at primary school if they are above 6.5 years of age at the start of the scholastic year in September. Since 2010 the attendance of at least 9 months of a free preschool program is compulsory.
} 


\subsection{The sample}

We use first-hand collected data obtained through a survey conducted with 300 Roma households of Belgrade, originally aimed at evaluating a remedial education program introduced in Serbia in 2009. ${ }^{13}$ All surveyed households have at least one child in the lower four grades of primary school in the year of the survey. They were randomly selected among pupils attending primary schools that were involved in the program at different points in time.

Belgrade is divided into 17 municipalities, among which 10 have Roma settlements, as defined by a population of at least 15 households or 100 individuals [Jaksic and Basic (2010)]. Five of these municipalities are included in our survey design, as the five remaining had no schools involved in this initial stage of the remedial program. ${ }^{14}$ We suspect that schools in those municipalities did not satisfy the eligibility criterion of having a share of Roma pupils between $5 \%$ and $40 \%$. $^{15}$ The municipalities included in the final sample host $59 \%$ of all Belgrade schools. Using MICS (2010), we estimate that our survey design amounts to randomly select pupils from schools enrolling $40 \%$ of all Roma children in primary school age. ${ }^{16}$ The survey took place in Fall 2010. The response rate was 93.46\%: 321 households had been contacted and 300 answered. Households were not compensated for their participation.

We acknowledge our survey design suffers from some limitations: we consider women with (i) at least one child aged 6-10; (ii) the child needs to be enrolled in a school; and (iii) schools need to have between $5 \%$ and $40 \%$ of Roma pupils. While we agree that this pool is certainly different in various ways from the universe of all Roma women, we nonetheless think that the concerns relative to the representativeness of the sample can be mitigated. Indeed, in Serbia, enrollment of Roma aged 6-10 into schools is close to universal and there are not any documented gender differences that could affect our results. Dropouts from primary schools usually arise after the first cycle of 4 years, when children are supposed to enter the second cycle of primary education [Open Society Institute (2007); Battaglia and Lebedinski (2015)]. Because schools with less than 5\% of Roma pupils are not selected in the program, we are aware that we might have under-sampled families living in settlements with few Roma households. Nonetheless, the lack of available official data on the actual distribution of Roma in Belgrade does not allow us to quantify the resulting bias. MICS (2010) Roma sample itself is formed by excluding all enumeration areas with 17 or less Roma households, sampling thus from a pool of $46 \%$ of the all Roma households. We believe though that we most likely underestimate differences associated with segregation as we trim the sample from its most desegregated households.

The design of the sample also implies that all households observed count at least one child. This may distort the representativity of the results in terms of fertility of the whole

\footnotetext{
${ }^{13}$ The Roma Teaching Assistant Program is the main program in Central and Eastern Europe aimed at improving inclusion of Roma in education. For a more extensive description of the program see Battaglia and Lebedinski (2015).

${ }^{14}$ The five municipalities are Voždovac, Zvezdara, Zemun, Palilula, and Čukarica.

${ }^{15}$ Most probably, the share of Roma pupils in those schools was lower than $5 \%$, as opposed to higher than $40 \%$, as these municipalities had smaller shares of Roma overall.

${ }^{16}$ The number of Roma children aged 6-9 in Belgrade is 3,029 [MICS (2010)] and the number of Roma children aged 6-9 in the schools from our survey is 1,170 .
} 
Roma population as it de facto removes the extensive margin of the fertility decision [or childlessness as put by Gobbi (2013) and Baudin et al. (2015)]. Using Census data for 2011, we obtain that the rate of childlessness of women over 39 in the Belgrade region was of $7 \%$ for Roma and $13 \%$ for Serbs. Though substantial, the magnitude of this difference is not likely to explain fully the much higher fertility of Roma women. We thus consider that studying only the intensive margin of the fertility decision is an important step per se.

Figure 1 displays a map of Belgrade with the 13 settlements where the survey was carried out. We use the definition of settlements from an NGO called the Society for Improvement of Roma Settlement, which made an inventory of the Roma presence in Belgrade in 2002 and classified it into clusters based on geographic concentration, natural and urban frontiers, as well as origin and time of in-migration. The number of households selected from each settlement is proportional to its size.

We classify settlements as composed of either only Roma people, mostly Roma people, or few Roma people. In the survey, we asked respondents whether in their community/neighborhood, defined as the area corresponding to 200 square meters around their house, there were only Roma people or both Roma and non-Roma. In the latter case, we further asked whether Roma were a minority or a majority. Notice that the definition of neighborhoods here does not exactly coincide with our settlements. Indeed, a neighborhood generally does not cover the entirety of a settlement, but conversely, the neighborhood of someone living at the periphery of the settlement may extend besides the settlement's limits. This is why we use the median perception about own neighborhood in the settlement. In almost two-third of the settlements, all households have the same perception. In the remaining third, there are either a few only Roma in a settlement otherwise perceived as mostly Roma, or the other way around. We believe that taking the median perception, because it smooths out potential outliers in individual perceptions, actually gives a relatively accurate and reliable representation of the reality.

We do not use metrics that are more commonly employed in the segregation literature such as the index of dissimilarity because there is no available information on the total Roma population residing in one particular area of Belgrade. The lack of official data on ethnic composition at the municipality level is one of the reasons why our data-though with some limitations-are a useful source of information.

Our data include household members' demographic characteristics, such as education level, religion, language spoken at home, and information on their dwellings. We also have detailed information on their settlement of residence from the database of Roma settlements, such as the number of inhabitants and main current utilities.

Panel A in Table 1 reports households' characteristics for the 13 settlements in our sample in column 1. Overall, they are in line with official data [LSMS (2007); MICS (2010)], as reported in Table B in the Appendix. On average, women in our sample are 32.5 years old, which is slightly older than those of the MICS sample. This is consistent with our conditioning on having at least one child enrolled in the four lower grades of primary school. As a consequence of this age difference, we also observe that women in our sample are slightly less educated (as educational attainment has risen slightly in recent cohorts), that the share of children below 6 is smaller, while that of children between 6 and 14 is larger, and that the number of adults in the household, and particularly older adults, is smaller. However and importantly for our analysis, the age at first birth as well as the total fertility rate in our sample are very 


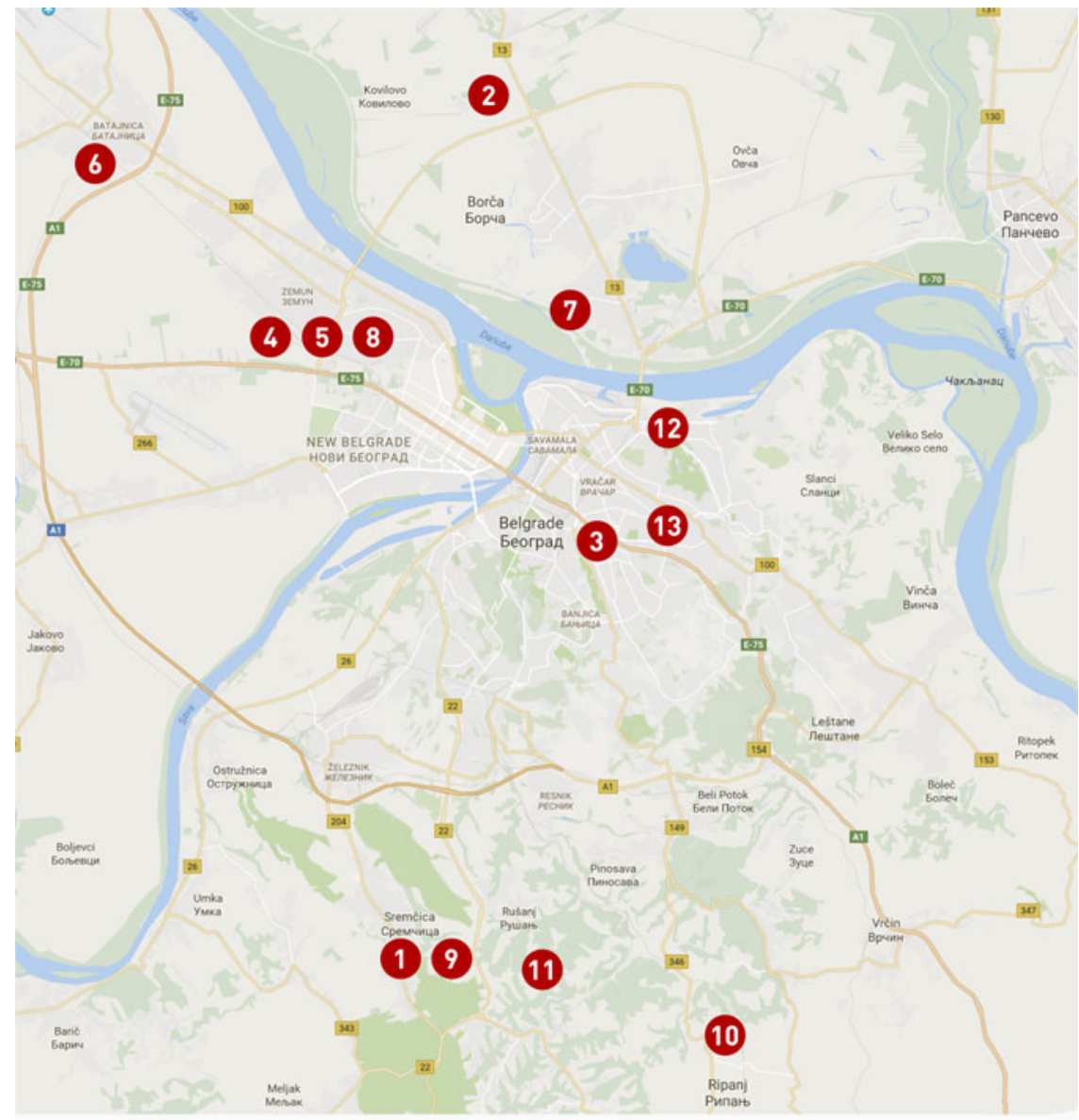
(1) SREMČICA BUNAR
6 BATAJNICA MRČINIŠTE
10 RIPANJ
2 DETELINA BORČA
(7) KOTEŽ NASIP II
(11) RUŠANJ
(3) MARINOKOVA BARA
8 VOJNI PUT BLOKI
(4) BAČKI ILOVNIK
(9) SREMČICA
12 VUKA VRČEVIĆA
(13) MALI MOKRI LUG
5 VOJNI PUT BLOK II

Figure 1. Map of Belgrade with settlements.

similar to those found in the MICS. ${ }^{17}$ The slightly larger fertility in the MICS may come from the fact that we measure fertility as the number of children alive at the time of the survey. This way, unlike the MICS, we disregard any child who did not survive.

\footnotetext{
${ }^{17}$ The total fertility rate is obtained by summing all the age-specific fertility rates over the reproductive cycle conventionally defined as age 15-49. It represents the total number of children a woman would have at the end of her reproductive cycle were she to experience successively all the age-specific rates of a given year. This measure does not depend on the age structure of the population.
} 
Table 1. Households' and settlements' characteristics

\begin{tabular}{|c|c|c|c|c|c|c|c|}
\hline \multirow[b]{3}{*}{ Variable } & \multirow[b]{2}{*}{ All } & \multirow[b]{2}{*}{$\begin{array}{l}\text { Only Roma } \\
\text { settlements }\end{array}$} & \multirow[b]{2}{*}{$\begin{array}{l}\text { Mostly Roma } \\
\text { settlements }\end{array}$} & \multirow[b]{2}{*}{$\begin{array}{l}\text { Few Roma } \\
\text { settlements }\end{array}$} & \multicolumn{3}{|c|}{ Normalized differences } \\
\hline & & & & & $(3)-(2)$ & $(4)-(2)$ & $(4)-(3)$ \\
\hline & (1) & $(2)$ & (3) & (4) & (5) & (6) & $(7)$ \\
\hline \multicolumn{8}{|l|}{ (A) Households' characteristics } \\
\hline \multirow[t]{2}{*}{ Mother's age } & 32.474 & 32.297 & 32.435 & 33 & 0.018 & 0.102 & 0.072 \\
\hline & $(5.606)$ & (4.799) & $(6.092)$ & $(4.961)$ & & & \\
\hline \multirow[t]{2}{*}{ Mother's literacy $(=1)$} & 0.793 & 0.74 & 0.811 & 0.739 & 0.125 & -0.120 & -0.005 \\
\hline & $(0.406)$ & $(0.442)$ & $(0.397)$ & $(0.449)$ & & & \\
\hline \multirow{2}{*}{$\begin{array}{l}\text { (Monthly) mother's income in } \\
\text { dinars }^{\mathrm{a}}\end{array}$} & 3,566 & 2,336 & 4,168 & 3,405 & 0.179 & 0.105 & -0.064 \\
\hline & $(7,793)$ & $(5,835)$ & $(8,397)$ & $(8,365)$ & & & \\
\hline \multirow{2}{*}{$\begin{array}{l}\text { (Monthly) father's income in } \\
\text { dinars }^{b}\end{array}$} & 15,114 & 14,061 & 16,040 & 13,189 & 0.100 & -0.045 & -0.135 \\
\hline & $(14,460)$ & $(12,789)$ & $(15,101)$ & $(14,793)$ & & & \\
\hline \multirow[t]{2}{*}{ Household wealth $^{c}$} & 0.092 & -0.097 & -0.015 & 0.938 & 0.036 & 0.440 & 0.437 \\
\hline & (1.594) & $(1.720)$ & $(1.476)$ & $(1.604)$ & & & \\
\hline \multirow{2}{*}{$\begin{array}{l}\text { Household source income } \\
\text { (=1 if formal sector job) }\end{array}$} & 0.489 & 0.527 & 0.478 & 0.459 & -0.069 & -0.095 & -0.026 \\
\hline & $(0.501)$ & $(0.503)$ & $(0.501)$ & $(0.505)$ & & & \\
\hline \multirow{2}{*}{$\begin{array}{l}\text { Household source income } \\
\text { (=1 if social benefits) }\end{array}$} & 0.158 & 0.149 & 0.161 & 0.162 & 0.025 & 0.026 & 0.001 \\
\hline & $(0.365)$ & $(0.358)$ & $(0.369)$ & $(0.374)$ & & & \\
\hline
\end{tabular}




\begin{tabular}{|c|c|c|c|c|c|c|c|}
\hline $\begin{array}{l}\text { Household source income (=1 } \\
\text { if informal sector job) }\end{array}$ & 0.353 & 0.324 & 0.360 & 0.378 & 0.053 & 0.079 & -0.026 \\
\hline & $(0.479)$ & $(0.471)$ & $(0.482)$ & $(0.492)$ & & & \\
\hline \multirow[t]{2}{*}{ Number of adults } & 2.272 & 2.500 & 2.168 & 2.27 & -0.268 & -0.154 & 0.215 \\
\hline & $(0.859)$ & $(1.037)$ & $(0.682)$ & $(1.071)$ & & & \\
\hline \multirow[t]{2}{*}{ Muslim (=1) } & 0.702 & 0.865 & 0.708 & 0.351 & -0.274 & -0.865 & -0.536 \\
\hline & $(0.458)$ & $(0.344)$ & $(0.456)$ & $(0.484)$ & & & \\
\hline \multirow{2}{*}{$\begin{array}{l}\text { Mother born in the same } \\
\text { settlement }(=1)\end{array}$} & 0.772 & 0.716 & 0.770 & 0.892 & 0.087 & 0.318 & 0.231 \\
\hline & $(0.42)$ & $(0.454)$ & $(0.422)$ & $(0.315)$ & & & \\
\hline \multirow{2}{*}{$\begin{array}{l}\text { Only Serbian names (adults) } \\
(=1)\end{array}$} & 0.176 & 0.203 & 0.303 & 0.405 & 0.098 & 0.506 & 0.406 \\
\hline & $(0.382)$ & $(0.268)$ & $(0.267)$ & $(0.498)$ & & & \\
\hline \multirow{2}{*}{$\begin{array}{l}\text { (Monthly) expected returns to } \\
\text { education in dinars } \\
\text { (street) }^{d}\end{array}$} & 1,694 & 1,681 & 1,720 & 1,607 & 0.040 & -0.083 & -0.155 \\
\hline & $(613)$ & $(770)$ & (561) & (463) & & & \\
\hline Obs. & 272 & 74 & 161 & 37 & & & \\
\hline \multicolumn{8}{|l|}{ (B) Settlements' characteristics } \\
\hline \multirow[t]{2}{*}{ Urban (=1) } & 0.417 & 0.333 & 0.429 & 0.667 & 0.121 & 0.408 & 0.303 \\
\hline & $(0.515)$ & $(0.577)$ & $(0.535)$ & $(0.577)$ & & & \\
\hline \multirow[t]{2}{*}{ Distance from school (min) } & 17.931 & 22.539 & 17.278 & 13.3015 & -0.599 & -1.521 & -0.469 \\
\hline & $(6.771)$ & (4.592) & (7.492) & (3.973) & & & \\
\hline \multirow[t]{2}{*}{ Distance from hospital (min) } & 20.694 & 27.249 & 19.331 & 15.630 & -0.839 & -1.446 & -0.607 \\
\hline & $(6.75)$ & (7.635) & $(5.55)$ & $(2.514)$ & & & \\
\hline
\end{tabular}


Table 1. (Continued.)

\begin{tabular}{|c|c|c|c|c|c|c|c|}
\hline \multirow{2}{*}{ Variable } & \multirow[b]{2}{*}{ All } & \multirow[b]{2}{*}{$\begin{array}{l}\text { Only Roma } \\
\text { settlements }\end{array}$} & \multirow[b]{2}{*}{$\begin{array}{l}\text { Mostly Roma } \\
\text { settlements }\end{array}$} & \multirow[b]{2}{*}{$\begin{array}{l}\text { Few Roma } \\
\text { settlements }\end{array}$} & \multicolumn{3}{|c|}{ Normalized differences } \\
\hline & & & & & (3) $-(2)$ & (4) $-(2)$ & (4) $-(3)$ \\
\hline Obs. & 12 & 3 & 7 & 3 & & & \\
\hline \multicolumn{8}{|l|}{ (C) Fertility outcomes } \\
\hline Number of children & (1.243) & (1.434) & $(1.161)$ & $(1.023)$ & & & \\
\hline \multirow[t]{2}{*}{ Proportion of boys } & 0.539 & 0.495 & 0.551 & 0.578 & 0.148 & 0.195 & 0.064 \\
\hline & $(0.278)$ & $(0.269)$ & $(0.267)$ & $(0.334)$ & & & \\
\hline Obs. & 272 & 74 & 161 & 37 & & & \\
\hline
\end{tabular}

Columns 5,6 , and 7 represent normalized differences, in bold when statistically significant at the $5 \%$ level.

a 3,643 dinars correspond to roughly 35 euros ( 1 RSD $=0.009626$ euros, November 2011).

${ }^{b} 15,209$ dinars correspond to roughly 146 euros ( 1 RSD $=0.009626$ euros, November 2011).

${ }^{\mathrm{c}}$ The wealth index ranges between -3.135 and 2.865 .

${ }^{d} 1,709$ dinars correspond to roughly 17 euros ( 1 RSD $=0.009626$ euros, November 2011). 
Wealth is measured by the first component of a principal component analysis on the presence in the household of various durables and utilities. ${ }^{18}$ Women received an average monthly income of 3,600 Serbian dinars, which is worth around 35US\$, while men made over four times that amount, about 15,000 Serbians dinars, or 150US\$. Households mainly receive income from labor, either in the formal or informal sector, rather than social transfers. ${ }^{19}$

Almost all households in the sample are nuclear with on average a little over two adults, although there are a few exceptions with more than four. They are most likely Muslim and never moved from the settlement they are currently living in. In total, $30 \%$ of households comprise adults named with only Serbian names. ${ }^{20}$ They expect that one extra year of schooling increases monthly income by roughly 17US\$, corresponding to $5 \%$ of the minimum wage. ${ }^{21}$ Roma people usually do not perform jobs for which high levels of education are required. They mainly work in the informal sector, without written contracts, often self-employed especially in flea markets and more rarely in factories [LSMS (2007)]..$^{22}$

Columns 2, 3, and 4 report separately means for only, mostly, and few Roma settlements. Households are overall comparable in terms of observable characteristics across settlement types: many normalized differences are smaller than one fourth of the combined sample variation, suggesting that linear regression methods are unlikely to be sensitive to specification changes [Imbens and Wooldridge (2009)]. The differences in means are not statistically significant in almost all cases between only and mostly. More substantial differences are found between only or mostly and few. Wealth and households with only Serbian names are higher in few Roma, while share of Muslims is lower.

Panel B of Table 1 reports the characteristics of the settlements. Households are equally located in urban and suburban areas, but only Roma settlements are more likely to be located in suburban areas. ${ }^{23}$ Settlements do also vary in their access to schools and hospitals, few Roma settlements being better connected. While those could influence fertility through their impact on infant mortality, access to contraceptives or family planning services, as well as the cost of child quality, we

\footnotetext{
${ }^{18}$ Filmer and Pritchett (2001) showed that an index obtained through the first principal component can provide reasonable estimates of the wealth level effects in situations where wealth data are not directly available.

${ }^{19}$ Source of income is equal to 1 when the main source of income is a job in the formal sector, 2 when it is social benefits, and 3 when it is a job in the informal sector.

${ }^{20}$ Examples of Serbian names are Aleksandar, Borislav, Ivan, Jelena, Katarina, and Slobodan. Examples of Romani names are Alvin, Djemila, Djulijana, Ersijana, Nuredin, Roberto, and Valentino. Romani names are different enough from Serbian names to clearly identify the ethnicity one belongs to [Behind the name (2017)].

${ }^{21}$ Expected returns to education were computed using questions in our survey about the salary parents expected for their children in different scenarios: no schooling, primary, and secondary. We construct Mincerian expected returns by regressing log-income on years of education. We find that one more year of schooling increases expected log earning by $9.4 \%$ for boys and $8.1 \%$ for girls, in line with what is observed in the literature [Duflo (2001); Hanushek and Welch (2006); Nguyen (2008); Jensen (2010); Montenegro and Patrinos (2013); Baudin et al. (2015)].

${ }^{22}$ More information on the Roma labor market in Serbia can be found in Battaglia and Lebedinski (2017).

${ }^{23}$ We define as urban area a local community with more than 35,000 inhabitants, in line with the definition of the Municipality of the City of Belgrade that distinguishes between urban and suburban areas on its own territory.
} 
believe that these differences should not play a role in the gender imbalances in terms of birth timing, therefore not compromising our general conclusions.

On average, Roma women in our sample have 3.2 children currently alive, of which $54 \%$ are boys (panel C of Table 1). A preliminary investigation of our outcome of interest shows that the number of children is significantly lower in few Roma settlements than in the other types of settlements. ${ }^{24}$ On average, in few Roma neighborhoods there are 2.8 children per household, while in mostly Roma and in only Roma neighborhoods there are, respectively, 3.2 and 3.6 children per household. The proportion of boys is not significantly different across the three groups, with slightly more boys in families in few Roma settlements.

\section{Empirical strategy and results}

\subsection{OLS results}

The summary statistics show that households in only Roma settlements have a higher fertility. Nonetheless, they could be the reflection of different age structures, socio-economic conditions, family arrangements, or returns to education. In this section, we test whether the gap in fertility across more or less-segregated settlements persists once we take into account household and settlement characteristics. To do so, we estimate the following regression equation using ordinary least squares (OLS $)^{25}$ :

$$
F_{i j s}=\beta_{0}+\beta_{1} \text { mostly_roma } s+\beta_{2} \text { few_roma } s+\gamma_{1} X_{i j s}+\delta_{1} S_{s}+\epsilon_{i j s}
$$

where $F_{i j s}$ stands for the number of living children for woman $i$ in household $j$ in settlement $s$ and mostly_roma and few_roma $_{s}$ are dummies equal to 1 if the household $j$ lives in a mostly or few Roma settlement, respectively, the omitted category being only Roma.

The set of individual and household characteristics $X_{i j s}$ and the vector of observable settlement characteristics $S_{s}$ include controls for different mechanisms that could affect fertility. First, mother's age and age squared are present in all specifications, in order to make sure that our results are not driven by differences in the age structure of the female population across settlements. Columns 2 through 6 in all tables test each of the mechanisms mentioned in the Introduction. In column 2, we include mothers' literacy and income, which are our closest proxies for the opportunity cost of female time, husband's income, as more bargaining power to men may translate in a larger family, household wealth, because richer household may afford more children, and the main source of income (either from social benefits, informal, or formal employment). ${ }^{26}$ In column 3 instead, we add expected returns to education, which may influence the way parents allocate resources to quality vs. quantity of children. ${ }^{27}$ In column 4, we use the number of adults in the household, to capture the fact that grandparents may help in taking care of larger cohorts of children. In column 5, we

\footnotetext{
${ }^{24} \mathrm{We}$ observe only children alive at the time of the survey and not the number of children ever born.

${ }^{25} \mathrm{We}$ also use a Poisson model in order to take into account the fact that fertility is a count variable. Results are consistent and reported in Table $\mathrm{C}$ in the Appendix.

${ }^{26}$ Ashraf $e t$ al. (2014) find that a larger bargaining power of women did increase contraceptive use and reduce fertility in the context of an experiment in Zambia.

${ }^{27}$ See the contributions by Kaufmann and Attanasio (2014), Jensen (2010), and Nguyen (2008) for the impact of perceived returns to education on investment in education.
} 
control for whether the settlement is in an urban or suburban area as a proxy for the cost of space. In column 6, we include cultural variables such as religion and whether parents' names are of Serbian origin. ${ }^{28}$ Indeed families who declare being Christian Orthodox or whose first names sound typically Serbian might have been more influenced by Serbian cultural and social norms, among which that of having a small number of children. ${ }^{29}$ Finally in column 7 , we keep controls for all mechanisms and test their robustness.

Robust standard errors are clustered at the settlement level with Moulton confidence intervals in the case of linear regressions [Imbens and Kolesár (2016)]. Results of specification 1 are presented in Table 2 .

The first striking result is that fertility differences documented in the descriptive statistics persist once controlled for individual, household, and settlement characteristics. In particular, women living in mostly Roma settlements seem to have about between a third and a quarter fewer children than those in only Roma locations, but the coefficient is not always precisely estimated. More importantly, women in few Roma settlements have around 0.5-0.8 fewer children than similar women in only Roma locations, and that difference is significant at the $1 \%$ level in all specifications. Such a large fertility gap across settlement is surprising as differences in individual characteristics did not seem particularly large (see Table 1) but also because Roma are usually regarded as a culturally homogeneous group.

The second observation is that adding controls in columns 2-6 tends to reduce the fertility gap, while including all controls reduces it by even more, as shown in column 7. Among significant controls, mothers' income and household wealth are strongly negatively associated with fertility, suggesting that the poorest households and households where mothers have a lower opportunity cost of time tend to have larger families. These results confirm previous findings, for instance by Jensen (2012), who finds that improved labor market opportunities not only substantially increase women's investment in education but as well delay marriage and fertility. The source of income instead does not seem to matter, while husband's income is positively related to a larger family. This suggests that a higher fertility is associated with a more pronounced specialization in the household.

Similarly, number of adults in the household and urban status, which are included to capture, respectively, different types of family arrangements and different housing prices, barely affect fertility. Higher-perceived returns to education instead are strongly associated with a lower fertility, which illustrates the presence of a quality/ quantity trade-off. A one standard deviation change in perceived returns to education is associated with a fall in fertility of 0.2 child. Battaglia and Lebedinski (2017) use the same data to show how enhancing people's perceived returns to education can impact positively labor market prospects and educational attainment.

Finally, religious affiliation does not seem to matter much, whereas exposure to the Serbian culture, as measured by whether parents hold Serbian sounding first names, is a strong predictor of a lower fertility. Indeed, shifting the prevalence of Serbian names

\footnotetext{
${ }^{28}$ More precisely, the religion dummy takes value 1 when Muslim and 0 when Christian Orthodox and other religions, but only $0.73 \%$ of our sample declares to practice another religion. We make use of the sounding of first names to capture acculturation in the spirit of recent papers such as Algan et al. (2013), Abramitzky et al. (2016), Jurajda and Kovač (2016), and Fouka (2019).

${ }^{29}$ In Serbia, $84 \%$ of the population is Christian Orthodox, $5 \%$ is Catholic, and 3\% is Muslim. The remaining $8 \%$ includes other religions, Atheists, and people who do not declare their faith [MICS (2010)].
} 
Table 2. Number of children-OLS

\begin{tabular}{|c|c|c|c|c|c|c|c|}
\hline & (1) & (2) & (3) & (4) & (5) & (6) & (7) \\
\hline & \multicolumn{7}{|c|}{ All columns are estimated using OLS } \\
\hline \multirow[t]{2}{*}{ Mostly Roma } & $-0.341^{*}$ & $-0.290^{\star \star}$ & $-0.326^{\star \star}$ & -0.337 & $-0.352^{*}$ & -0.273 & $-0.215^{\star \star}$ \\
\hline & $(0.185)$ & $(0.117)$ & $(0.125)$ & $(0.222)$ & $(0.189)$ & $(0.168)$ & $(0.094)$ \\
\hline \multirow[t]{2}{*}{ Mother's literacy } & & -0.150 & & & & & -0.152 \\
\hline & & $(0.208)$ & & & & & $(0.207)$ \\
\hline \multirow[t]{2}{*}{ Mother's income } & & $-0.027^{\star \star \star}$ & & & & & $-0.021^{\star \star \star}$ \\
\hline & & $(0.004)$ & & & & & $(0.006)$ \\
\hline Household wealth & & $(0.055)$ & & & & & $(0.057)$ \\
\hline \multicolumn{8}{|c|}{ Source income-formal sector job (baseline) } \\
\hline \multirow[t]{2}{*}{ Social benefits } & & 0.198 & & & & & 0.305 \\
\hline & & $(0.165)$ & & & & & $(0.208)$ \\
\hline \multirow[t]{2}{*}{ Informal sector job } & & $0.316^{*}$ & & & & & 0.302 \\
\hline & & $(0.164)$ & & & & & $(0.174)$ \\
\hline
\end{tabular}




\begin{tabular}{|c|c|c|c|c|c|c|c|}
\hline \multirow[t]{2}{*}{ Expected returns to education } & & \multicolumn{3}{|c|}{$-0.350^{\star \star \star}$} & & & $-0.293^{\star \star \star}$ \\
\hline & & \multicolumn{3}{|c|}{$(0.084)$} & & & $(0.078)$ \\
\hline \multirow[t]{2}{*}{ Number of adults } & & \multicolumn{4}{|c|}{0.012} & & 0.139 \\
\hline & & \multicolumn{4}{|c|}{$(0.142)$} & & $(0.128)$ \\
\hline \multirow[t]{2}{*}{ Urban } & & & & \multicolumn{3}{|c|}{0.067} & -0.040 \\
\hline & & & & \multicolumn{3}{|c|}{$(0.157)$} & $(0.102)$ \\
\hline \multirow[t]{2}{*}{ Muslim } & & & & & & 0.166 & -0.021 \\
\hline & & & & & & $(0.202)$ & $(0.213)$ \\
\hline \multirow[t]{2}{*}{ Only Serbian names } & & & & & & $-0.682^{\star \star}$ & -0.403 \\
\hline & & & & & & $(0.234)$ & $(0.280)$ \\
\hline Mother's age and age squared & $x$ & $\mathrm{x}$ & $x$ & $x$ & $x$ & $x$ & $x$ \\
\hline Obs. & 272 & 271 & 272 & 272 & 272 & 272 & 271 \\
\hline$r^{2}$ & 0.059 & 0.205 & 0.089 & 0.059 & 0.060 & 0.116 & 0.239 \\
\hline \multicolumn{8}{|l|}{ Test for the difference in coefficients } \\
\hline Mostly Roma and few Roma ( $p$-value) & 0.0125 & 0.1386 & 0.0105 & 0.0129 & 0.0087 & 0.3724 & 0.1498 \\
\hline
\end{tabular}

Robust standard errors clustered at the settlement level with Moulton confidence intervals in parentheses: ${ }^{*} p<0.10,{ }^{* \star} p<0.05,{ }^{* \star *} p<0.01$. 
from that in few Roma settlements down to the one observed in only Roma locations is associated with an increase in fertility of about 0.14 child.

When all controls are included together, the gaps between mostly Roma and only Roma and between only Roma and few Roma decrease in size but remain highly statistically significant. Most of the channels that appear significant taken separately remain significant, except for Serbian names. However, the fact that it is not enough to close the gap indicates that several of these factors are probably confounded and that we do not estimate causal effects.

In Table D in the Appendix, we focus on the subsample of women who reside in their settlement of birth. The rationale for this exercise is to avoid that what we claim is associated with segregation is actually due to recent migration patterns. Mothers who were born in the settlement in which they reside tend to be richer and to have significantly fewer children on average. Examination of the table however shows that the exact same pattern emerges regarding the comparison between only, mostly, or few Roma settlements. We can therefore be reassured that recent migration waves were not responsible for the higher fertility observed in more-segregated areas.

We finally investigate the robustness of these associations using alternative measures of segregation in Table E in the Appendix. Results remain qualitatively consistent using the median perception about whether the neighborhood is only, mostly, or few Roma at the street level rather than at the settlement level.

\subsection{Birth timing and son preference}

In the previous subsection, we have examined the number of children women have controlling for a second-order polynomial in their age. It implicitly imposes a structured, though quite flexible, relationship between age and the number of children that is common to all women in the sample. Our conclusions are therefore valid for completed fertility if birth timing does not differ significantly across settlement types.

In this subsection instead, we do away with this assumption by analyzing the pace at which women give birth instead of their total number of children only. In addition to confirming the conclusions drawn from the analysis of total number of children, examining birth timing allows us to investigate whether there are gender-specific patterns. Indeed, in a context where sex-selective abortion is not significantly used, looking at the sex ratio at birth is not informative. Instead, son preference can be detected by looking either at the difference in waiting time after having a boy vs. having a girl or at the sex ratio of last birth as originally suggested by Dalla Zuanna and Leone (2001).

To this end, we start by using a proportional hazard model, which leaves the baseline hazard rate unspecified and assumes that it is shifted multiplicatively by covariates. ${ }^{30}$ We look separately at first births and then all subsequent births. In the first case, we define the at-risk period as starting at age 14, while we make it start 9 months after the previous birth we observe in the latter case. We acknowledge a potential limitation for first births as we observe only children still in the household at the time of the survey, which may differ from the universe of all births. Indeed some of

\footnotetext{
${ }^{30}$ We test the proportional hazard assumption. As reported in Figure $\mathrm{A}$ in the Appendix, the curves representing the $\log (-\log ($ survival $))$ vs. the $\log$ of survival time for different settlement types are roughly parallel, providing evidence in its favor.
} 
the oldest mothers in the sample may have had an early child who already left the sample and whom we consequently do not observe. Imbalances in the sex ratio of first born children confirm our hypothesis, as reported in Figure B in the Appendix. The at-risk period ends either with a birth or with the woman actually leaving the sample (i.e., when the running variable reaches her age at the time of the survey). Notice that now the unit of observation is the post birth spell and not the mother, hence the increase in the number of observations. Covariates are assumed to affect the baseline hazard multiplicatively, so that the equation we estimate is the following:

$$
h\left(t \mid x_{\mathrm{c}}\right)=h_{0}(t) e^{x_{\mathrm{c}} \beta_{\mathrm{x}}}
$$

where $x_{\mathrm{c}}$ includes the same controls as in the previous subsection. Robust standard errors are clustered at the settlement level with Moulton confidence intervals.

The baseline results shown in Table 3 shed some further light on the findings from the previous subsection. Panel A indicates that there are no significant differences in the timing of first births, while panel B adds that women living in few Roma settlements have subsequent children at a significantly slower pace than their mostly or only Roma counterparts. The coefficient -0.449 on few Roma in column 1 corresponds to women in these neighborhoods being 36\% less likely to have an extra child than comparable women living in an only Roma settlement. Controlling for potential mechanisms reduces but does not close the gap between settlements with different levels of segregation. As before, we investigate the robustness of the analysis by using an alternative measure of segregation at the street level. Results remain consistent, as reported in Table $\mathrm{F}$ in the Appendix.

Then we turn to whether birth timing differs according to the gender of the previously born child. To this end, we interact our measure of segregation with a dummy indicating whether the previously born child was a male or a female. ${ }^{31}$ To make sure that children leaving the household early on do not introduce too much error in the measurement of the gender of the previously born or first born child, we choose to restrict the sample to mothers below 33 years of age. ${ }^{32}$ Results are presented in Table 4.

The main result to highlight in this table is that the difference in birth spacing across settlement types comes mostly from the difference in birth spacing after a boy was born. Indeed, households in only Roma and mostly Roma do not exhibit significantly different spacing patterns after boys or girls. However, households living in a few Roma settlement tend to space substantially more after a boy, which is illustrated by the coefficient on "few Roma-male." The coefficients in column 1 indicate that the hazard ratio of having an extra child after a male is $23 \%$ smaller than after a girl for households in only Roma settlements (but this difference is not statistically different from zero), while it is $58 \%$ smaller in the case of few Roma households. This latter difference is significantly different from zero at the $5 \%$ level. The same pattern

\footnotetext{
${ }^{31}$ This is related in spirit to a recent contribution by Dimri et al. (2017) who analyze the patterns of birth spacing in function of the gender of the next born, in the presence of sex-selective abortions.

${ }^{32}$ Figure $B$ in the Appendix plots the sex-ratio of children in the sample as we vary the upper age limit of mothers. It shows very clearly that sex-ratios are around the biological level for mothers aged 33 or below, while they become very skewed when we include older mothers. We suspect that this is because daughters tend to leave the household earlier than sons.
} 
Table 3. Birth spacing by settlement type

\begin{tabular}{|c|c|c|c|c|c|c|c|}
\hline & $(1)$ & $(2)$ & (3) & (4) & (5) & (6) & (7) \\
\hline & \multicolumn{7}{|c|}{ All columns are estimated using a Cox proportional hazard model } \\
\hline \multicolumn{8}{|l|}{ Panel A: Timing of first births } \\
\hline \multicolumn{8}{|c|}{ Level of segregation-only Roma (baseline) } \\
\hline \multirow[t]{2}{*}{ Mostly Roma } & 0.052 & 0.108 & 0.058 & 0.025 & 0.032 & 0.094 & 0.128 \\
\hline & $(0.085)$ & $(0.077)$ & $(0.091)$ & $(0.093)$ & $(0.085)$ & $(0.059)$ & $(0.082)$ \\
\hline \multirow[t]{2}{*}{ Few Roma } & -0.019 & 0.067 & -0.024 & -0.041 & -0.085 & 0.072 & 0.077 \\
\hline & $(0.060)$ & $(0.057)$ & $(0.105)$ & $(0.075)$ & $(0.125)$ & $(0.094)$ & $(0.115)$ \\
\hline Obs. & 272 & 271 & 271 & 272 & 272 & 272 & 271 \\
\hline \multicolumn{8}{|l|}{ Panel B: All subsequent births } \\
\hline \multicolumn{8}{|c|}{ Level of segregation-only Roma (baseline) } \\
\hline \multirow[t]{2}{*}{ Mostly Roma } & -0.157 & -0.144 & -0.134 & -0.128 & -0.171 & -0.122 & -0.097 \\
\hline & $(0.126)$ & $(0.109)$ & $(0.101)$ & $(0.151)$ & $(0.126)$ & $(0.130)$ & $(0.133)$ \\
\hline \multirow[t]{2}{*}{ Few Roma } & $-0.449^{\star \star *}$ & $-0.397^{\star \star \star}$ & $-0.466^{\star \star \star}$ & $-0.427^{\star \star \star}$ & $-0.477^{\star \star \star}$ & $-0.322^{*}$ & $-0.326^{\star *}$ \\
\hline & $(0.156)$ & $(0.126)$ & $(0.137)$ & $(0.158)$ & $(0.159)$ & $(0.191)$ & $(0.136)$ \\
\hline Mother's age and age squared & $x$ & $x$ & $x$ & $x$ & $x$ & $x$ & $x$ \\
\hline Opportunity cost of time ch. & & $x$ & & & & & $x$ \\
\hline Expected return to education & & & $x$ & & & & $x$ \\
\hline Number of adults & & & & $x$ & & & $x$ \\
\hline Urban & & & & & $x$ & & $x$ \\
\hline Cultural ch. & & & & & & $x$ & $x$ \\
\hline Obs. & 881 & 879 & 864 & 881 & 881 & 881 & 879 \\
\hline
\end{tabular}

Robust standard errors clustered at the settlement level with Moulton confidence intervals in parentheses: ${ }^{\star} p<0.10,{ }^{\star \star} p<0.05,{ }^{\star \star \star} p<0.01$. 
Table 4. Birth spacing by settlement type and gender of previously born child-sample of women aged 33 or less

\begin{tabular}{|c|c|c|c|c|c|c|c|}
\hline & (1) & $(2)$ & (3) & (4) & (5) & (6) & (7) \\
\hline & \multicolumn{7}{|c|}{ All columns are estimated using a Cox proportional hazard model } \\
\hline \multicolumn{8}{|c|}{ Previously born: female-level of segregation: only Roma (baseline) } \\
\hline \multirow[t]{2}{*}{ Female-mostly Roma } & -0.091 & -0.031 & -0.104 & -0.062 & -0.101 & -0.071 & 0.019 \\
\hline & $(0.123)$ & $(0.114)$ & $(0.109)$ & $(0.135)$ & $(0.156)$ & $(0.132)$ & $(0.135)$ \\
\hline \multirow[t]{2}{*}{ Female-few Roma } & -0.113 & 0.032 & -0.132 & -0.091 & -0.124 & 0.031 & 0.187 \\
\hline & $(0.091)$ & $(0.143)$ & $(0.082)$ & $(0.093)$ & $(0.100)$ & $(0.205)$ & $(0.189)$ \\
\hline \multirow[t]{2}{*}{ Male-only Roma } & -0.258 & -0.247 & -0.275 & -0.257 & -0.256 & -0.245 & -0.238 \\
\hline & $(0.195)$ & $(0.186)$ & $(0.202)$ & $(0.195)$ & $(0.202)$ & $(0.176)$ & $(0.170)$ \\
\hline \multirow[t]{2}{*}{ Male-mostly Roma } & 0.097 & 0.018 & 0.106 & 0.095 & 0.099 & 0.099 & 0.025 \\
\hline & $(0.258)$ & $(0.271)$ & $(0.265)$ & $(0.258)$ & $(0.256)$ & $(0.245)$ & $(0.255)$ \\
\hline \multirow[t]{2}{*}{ Male-few Roma } & $-0.604^{\star}$ & $-0.490^{\star}$ & $-0.581^{\star \star}$ & $-0.621^{\star \star}$ & $-0.606^{\star *}$ & $-0.565^{\star \star \star}$ & $-0.493^{\star *}$ \\
\hline & $(0.260)$ & $(0.273)$ & $(0.273)$ & $(0.252)$ & $(0.265)$ & $(0.215)$ & $(0.233)$ \\
\hline Mother's age and age squared & $x$ & $x$ & $\mathrm{x}$ & $\mathrm{x}$ & $\mathrm{x}$ & $\mathrm{x}$ & $x$ \\
\hline Opportunity cost of time ch. & & $x$ & & & & & $x$ \\
\hline Expected return to education & & & $x$ & & & & $x$ \\
\hline Number of adults & & & & $x$ & & & $x$ \\
\hline Urban & & & & & $x$ & & $x$ \\
\hline Cultural ch. & & & & & & $x$ & $x$ \\
\hline Obs. & 554 & 552 & 550 & 554 & 554 & 554 & 552 \\
\hline
\end{tabular}


emerges as controls are added: they allow us to close only partially the gap in birth timing across settlement types.

\subsection{Comparing son preference across Roma and non-Roma communities in Serbia}

In this subsection, we attempt to give further evidence that a cultural transmission process is at work. We use data on Roma and non-Roma populations from the MICS (2010) to analyze how their birth spacing patterns depend on the gender of the previously born child. We illustrate those patterns comparing the Kaplan-Meier survival curves for all births following a male baby to those following a female baby (which requires that we exclude first births) for both Roma and non-Roma. Results are shown in Figure 2. It appears that Roma and non-Roma Serbs exhibit a very similar pattern of shorter spells after a female baby. Table $G$ in the Appendix confirms that non-Roma populations do exhibit a low fertility-1.73 children per woman on average-and a longer spacing after boys than after girls. While this in theory could be driven by common determinants across communities, we believe it points at a phenomenon of cultural assimilation from the Roma minority into the Serbian majority. Indeed, our data reveal that these specific gender patterns are dominantly prevalent in Roma settlements where they are a minority surrounded by non-Roma populations, as shown in Figure 3.

While we are not aware of other studies documenting higher birth spacing after boys in Serbia or in other countries of the Western Balkans, high sex ratios at birth have been recently observed in several countries of the region [UNFPA (2012)]. ${ }^{33}$ According to Guilmoto and Duthé (2013), together with the fertility decline and the development of modern healthcare services, the persistence of traditional patriarchal values is central to the son preference observed in these countries. Conversely, traditional Roma societies, especially in rural areas, show a female-biased sex ratio at birth and invest more heavily in daughters since they are more likely than sons to help their parents in taking care of siblings [Bereczkei and Dunbar $(1997,2002)$ ].

As a final check that the birth spacing patterns observed do reveal a higher son preference in less-segregated Roma settlements as well as in non-Roma communities, we look at the sex ratio at last birth. Indeed, as originally suggested by Dalla Zuanna and Leone (2001), the sex ratio at last birth captures gender-biased preferences in a context where couples decide to halt fertility after the birth of a son. To focus on last births, we include women who have at least one child and have not had children in the past 5 years. The sex ratios at last birth are shown in Table $\mathrm{H}$ in the Appendix for our data on the left panel and for Roma and non-Roma in the MICS on the right panel.

The sex ratio at last birth appears to be significantly higher than 0.5 for Roma both in our data, at 0.596 , and in the MICS, at 0.564. Our data reveal that this skewness is largely driven by a very unbalanced ratio in few Roma settlements at 0.778 . The sex ratio at last birth for non-Roma in the MICS is much lower than that, at 0.528 , but statistically different from 0.5 and measured on a much larger sample. Ideally, we would like to measure the sex ratio at last birth of non-Roma populations that are in contact with Roma settlements. Unfortunately, this is not possible using MICS data.

\footnotetext{
${ }^{33}$ In Albania, the sex ratio hovers around 110 (a normal sex ratio is 105). In Montenegro, for the period 2009-2011, the sex ratio at birth was 109.8. In Kosovo, for the period 2011-2013, the sex ratio at birth was 110.4. In Serbia, for the period 2000-2005, the sex ratio at birth was 107.
} 

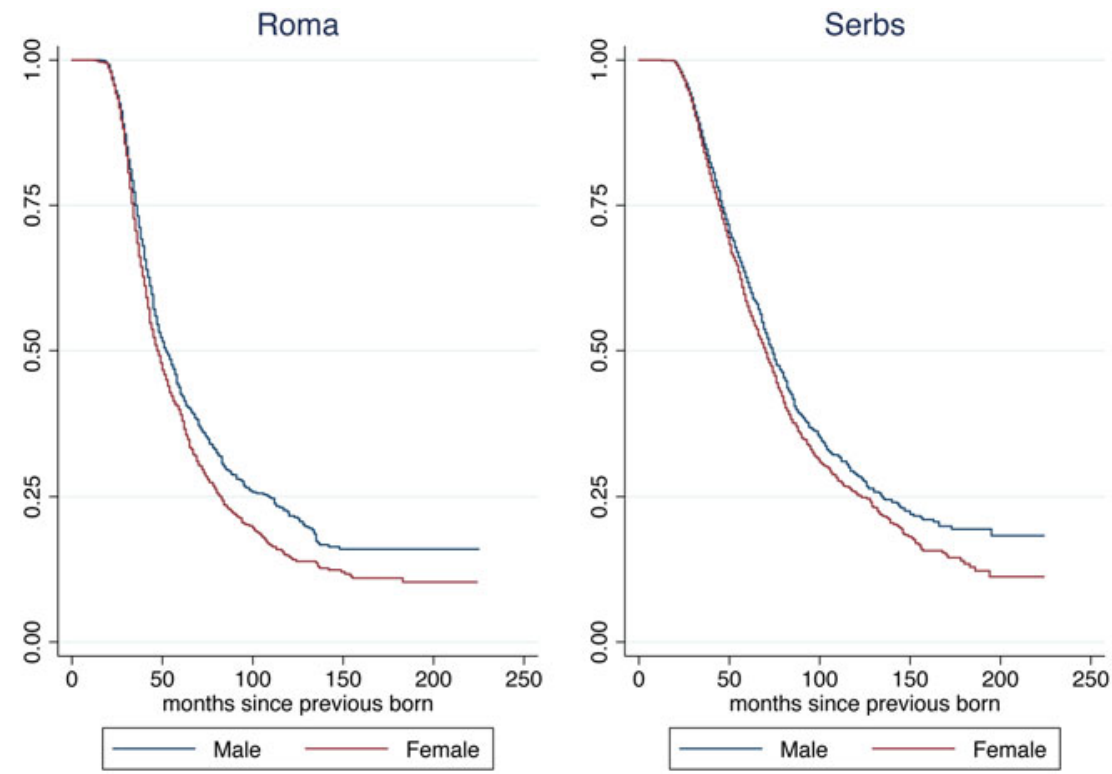

Figure 2. Kaplan-Meier survival curves by gender of the previously born child using MICS (2010) data.
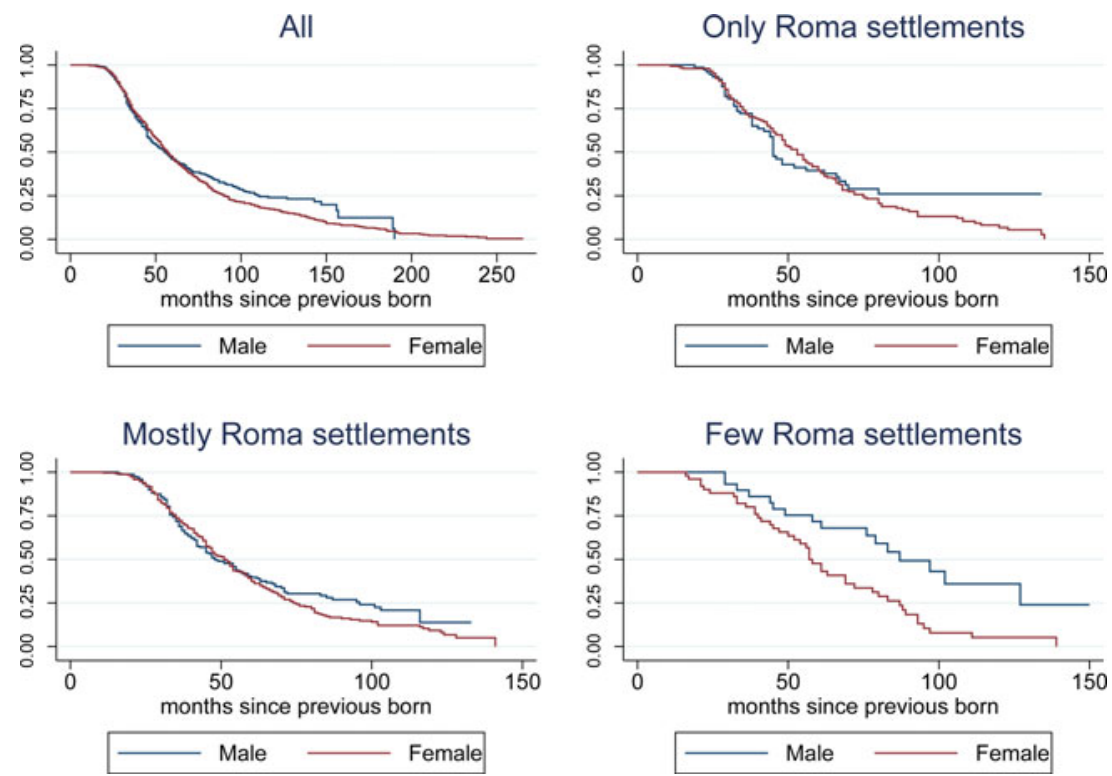

Figure 3. Kaplan-Meier survival curves by gender of the previously born child.

Ultimately, the sex ratio at last birth is an additional element pointing at a cultural transmission channel from the Serbian majority to the least-segregated Roma communities. 
The sex ratio at last birth points at the importance of differential stopping behavior. For comparison purposes, we reproduce Table 4 on a restricted sample limited to all censored inter-birth spells and censored post-birth spells of less than 5 years. The idea is to check whether inter-birth spacing behavior (excluding therefore differences in stopping behavior) also differs across settlement types. Results are shown in Table I in the Appendix. Although it appears that few Roma communities consistently space more after boys than girls, the picture is less clear-cut than in the overall sample, as mostly Roma do so as well to some extent. Additionally, few Roma also space comparatively more after girls than mostly and only Roma. Altogether, these results show that both spacing and stopping happen at a different rate after a son and after a daughter, but differential stopping behavior is key to illustrate the higher son preference in few Roma communities.

\section{Conclusion}

We provide evidence of substantial spatial disparities in fertility behavior across neighborhoods within a given supposedly homogeneous minority group. We find that fertility is lower and son preference more pronounced in Roma settlements that are less segregated from the rest of the Serbian society. Our analysis of the potential mechanisms points to the greater exposure of less-segregated areas to the Serbian culture, in which fertility tends to be low and boys preferred.

Our results suggest that cultural diffusion (or lack thereof) is an important factor to take into account while designing policies. Indeed, policies aiming at changing economic incentives of marginalized populations may remain inefficient for long time if these populations are severely segregated away from other fringes of the population. Policies promoting social mixing on the other hand could go a long way as exposure to different cultural norms seems conducive to rapid behavioral change. This could prove all the more powerful in the context of fertility choices as more evidence shows that decreasing fertility has been a key element triggering the take-off to the modern growth regime [Chatterjee and Vogl (2018)].

Supplementary material. The supplementary material for this article can be found at https://doi.org/ 10.1017/dem.2020.8.

Acknowledgments. We are especially indebted to the personnel of the Ipssos Strategic Marketing Agency for the successful data collection. We thank the Editor Murat Iyigun and four anonymous referees for their guidance in improving this manuscript. We are also grateful to David de la Croix, Anna Sanz-de-Galdeano, Lola Collado, Coralio Ballester, Pedro Albarran, and Iñigo Iturbe-Ormaetxe for helpful comments and suggestions. We benefited from valuable comments of seminar participants at IRES macro lunch seminars, Maastricht University Graduate School of Governance seminars, SAEe 2016, the 2017 summer academy on Family in Transition: Context, Values, and Choice (IOS), and 2017 ASREC Europe Conference. Financial support from the Spanish Ministry of Science and Innovation (Ref. ECO2014-58434-P), the Serbian Ministry of Education, Science and Technological Development (project number: OI 179015), and the Belgian French-speaking community (ARC convention 15/19-063 on "Family transformations") is gratefully acknowledged. All opinions expressed are of the authors, all errors are our own.

\section{References}

Abramishvili, Z., W. Appleman and S. Maksymovych (2019) Parental gender preference in the Balkans and Scandinavia: gender bias or differential costs? CERGE-EI Working Paper Series (623). 
Abramitzky, R., L. P. Boustan and K. Eriksson (2016) Cultural assimilation during the age of mass migration. Technical report, National Bureau of Economic Research.

Adsera, A. (2006) Marital fertility and religion in Spain, 1985 and 1999. Population Studies 60(2), 205-221.

Aisa, R., J. Andaluz and G. Larramona (2017) Fertility patterns in the Roma population of Spain. Review of Economics of the Household 15(1), 115-133.

Aisa, R. and G. Larramona (2014) Labour market outcomes in the Roma population of Spain. Munich Personal Repec Archive.

Aisa, R., G. Larramona and F. Pueyo (2016) Discrimination and self-reported health for the Spanish Roma. Public Health 134, 105-108.

Alesina, A., R. Baqir and W. Easterly (1999) Public goods and ethnic divisions. Quarterly Journal of Economics 114(4), 1243-1284.

Algan, Y., T. Mayer and M. Thoenig (2013) The economic incentives of cultural transmission: spatial evidence from naming patterns across France. Technical report.

Altindag, O. (2016) Son preference, fertility decline, and the non-missing girls of Turkey. Demography 53 (2), 541-566.

Anukriti, S. (2018) Financial incentives and the fertility-sex ratio trade-off. American Economic Journal: Applied Economics 10(2), 27-57.

Anukriti, S., S. Bhalotra and H. Tam (2018) On the quantity and quality of girls: fertility, parental investments, and mortality. Technical report. Boston College Department of Economics.

Ashraf, N., E. Field and J. Lee (2014) Household bargaining and excess fertility: an experimental study in Zambia. The American Economic Review 104(7), 2210-2237.

Battaglia, M. and L. Lebedinski (2015) Equal access to education: an evaluation of the Roma teaching assistant program in Serbia. World Development 76, 62-81.

Battaglia, M. and L. Lebedinski (2017) The curse of low expectations: remedial education and perceived returns to education of Roma people. Economics of Transition 25(4), 681-721.

Baudin, T., D. de la Croix and P. E. Gobbi (2015) Fertility and childlessness in the United States. The American Economic Review 105(6), 1852-1882.

Bayer, P., S. L. Ross and G. Topa (2008) Place of work and place of residence: informal hiring networks and labor market outcomes. Journal of Political Economy 116(6), 1150-1196.

Behind the name (2017) http://www.behindthename.com/names/usage.

Bereczkei, T. and R. I. M. Dunbar (1997) Female-biased reproductive strategies in a ethnic Hungarian Gypsy population. Proceedings of the Royal Society B: Biological Sciences 264, 17-22.

Bereczkei, T. and R. I. M. Dunbar (2002) Helping-at-the-nest and sex-biased parental investment in a Hungarian Gypsy population. Current Anthropology 43(5), 804-809.

Berman, E. (2000) Sect, subsidy, and sacrifice: an economist's view of ultra-orthodox Jews. Quarterly Journal of Economics 115(3), 905-953.

Blau, F., L. Kahn, A. Liu and K. Papps (2013) The transmission of women's fertility, human capital, and work orientation across immigrant generations. Journal of Population Economics 26(2), 405-435.

Blume, L. and S. Durlauf (2006) Identifying social interactions: a review. In Michael Oakes and Jay Kaufman (eds.), Methods in Social Epidemiology. Madison: University of Wisconsin.

Boeri, T., M. D. Philippis, E. Patacchini and M. Pellizzari (2015) Immigration, housing discrimination and employment. The Economic Journal 125(508), F82-F114.

Boustan, L. P. (2012) School desegregation and urban change: evidence from city boundaries. American Economic Journal: Applied Economics 4(1), 85-108.

Boustan, L. P. and R. A. Margo (2013) A silver lining to white flight? White suburbanization and African-American homeownership, 1940-1980. Journal of Urban Economics 78, 71-80.

Card, D. and J. Rothstein (2007) Racial segregation and the Black-White test score gap. Journal of Public Economics 91(11-12), 2158-2184.

Cervellati, M. and U. Sunde (2015) The economic and demographic transition, mortality, and comparative development. American Economic Journal: Macroeconomics 7(3), 189-225.

Chabé-Ferret, B. (2013) Socioeconomic characteristics, fertility norms and the Black-White fertility gap in the US. Technical report, Université catholique de Louvain, Institut de Recherches Economiques et Sociales.

Chabé-Ferret, B. (2019) Adherence to cultural norms and economic incentives: evidence from fertility timing decisions. Journal of Economic Behavior \& Organization 162, 24-48. 
Chabé-Ferret, B. and P. Melindi Ghidi (2013) Differences in fertility behavior and uncertainty: an economic theory of the minority status hypothesis. Journal of Population Economics 26(3), 887-905.

Chatterjee, S. and T. Vogl (2018) Escaping Malthus: economic growth and fertility change in the developing world. The American Economic Review 108(6), 1440-1467.

Clark, K. and S. Drinkwater (2002) Enclaves, neighbourhood effects and employment outcomes: ethnic minorities in England and Wales. Journal of Population Economics 7(5), 603-628.

Coleman, D. A. and S. Dubuc (2010) The fertility of ethnic minorities in the UK, 1960s-2006. Population Studies 64(1), 19-41.

Compton, J. and R. A. Pollak (2014) Family proximity, childcare, and women's labor force attachment. Journal of Urban Economics 79, 72-90.

Cutler, D. M. and E. L. Glaeser (1997) Are ghettos good or bad? Quarterly Journal of Economics 112(3), 827-872.

Dalla Zuanna, G. and T. Leone (2001) A gender preference measure: the sex-ratio at last birth. Genus 57(1), 33-56.

Daudin, G., R. Franck and H. Rapoport (2018) Can internal migration foster the convergence in regional fertility rates? Evidence from 19th century France. The Economic Journal 129(620), 1618-1692.

de la Croix, D. and F. Perrin (2018) How far can economic incentives explain the French fertility and education transition? European Economic Review 108, 221-245.

Dimri, A., V. Gille and P. Ketz (2017) Sex-selective abortion: are there repeated abortions? Technical report.

Doepke, M. (2015) Gary Becker on the quantity and quality of children. Journal of Demographic Economics 81(1), 59-66.

Duflo, E. (2001) Schooling and labor market consequences of school construction in Indonesia: evidence from an unusual policy experiment. The American Economic Review 91(4), 795-813.

Durlauf, S. (2004) Chapter 50 neighborhood effects. In J. V. Henderson and J.-F. Thisse (eds.), Cities and Geography, Volume 4 of Handbook of Regional and Urban Economics, pp. 2173-2242. Amsterdam, the Netherlands: Elsevier.

Durst, J. (2002) Fertility and childbearing practices among poor Gypsy women in Hungary: the intersections of class, race and gender. Communist and Post-Communist Studies 35(4), 457-474.

Edin, P.-A., P. Frederiksson and O. Åslund (2003) Ethnic enclaves and the economic success of immigrants: evidence from a natural experiment. Quarterly Journal of Economics 118(1), 329-357.

Fernández, F. and A. Fogli (2006) Fertility: the role of culture and family experience. Journal of the European Economic Association 4(2-3), 552-561.

Fernández, F. and A. Fogli (2009) Culture: an empirical investigation of beliefs, work and fertility. American Economic Journal: Macroeconomics 1(1), 146-177.

Filmer, D. and L. Pritchett (2001) Estimating wealth effects without expenditure data or tears: an application to educational enrollments in states of India. Demography 38(1), 115-132.

Forste, R. and M. Tienda (1996) What's behind racial and ethnic fertility differentials? Population and Development Review 22, 109-133.

Fouka, V. (2019) How do immigrants respond to discrimination? The case of Germans in the US during World War I. American Political Science Review 113(2), 405-422.

Galor, O. (2012) The demographic transition: causes and consequences. Cliometrica, Journal of Historical Economics and Econometric History 6(1), 1-28.

Galor, O. and D. N. Weil (1999) From Malthusian stagnation to modern growth. The American Economic Review 89(2), 150-154.

Galor, O. and D. N. Weil (2000) Population, technology, and growth: from Malthusian stagnation to the demographic transition and beyond. The American Economic Review 90(4), 806-828.

Gobbi, P. E. (2013) A model of voluntary childlessness. Journal of Population Economics 26(3), 963-982.

Goldscheider, C. and P. R. Uhlenberg (1969) Minority group status and fertility. American Journal of Sociology 74(4), 361-372.

Guilmoto, C. Z. and G. Duthé (2013) Masculinization of birth in Eastern Europe. Population and Societies (506).

Hablicsek, L. (2008) The development and the spatial characteristics of Roma population in Hungaryexperimental population projections till 2021. Demográfia English Edition 51(5), 85-123.

Hajdu, T., G. Kertesi and G. Kézdi (2017) Health differences at birth between Roma and non-Roma children in Hungary-long-run trends and decompositions. Technical Report 1712, Institute of Economics, Centre for Economic and Regional Studies, Hungarian Academy of Sciences. 
Hanushek, E. A. and F. Welch (2006) Handbook of the Economics of Education. Amsterdam, the Netherlands: North-Holland.

Hesketh, T. and Z. W. Xing (2006) Abnormal sex ratios in human populations: causes and consequences. Proceedings of the National Academy of Sciences 103(36), 13271-13275.

Imbens, G. W. and M. Kolesár (2016) Robust standard errors in small samples: some practical advice. The Review of Economics and Statistics 98(4), 701-712.

Imbens, G. and J. Wooldridge (2009) Recent developments in the econometrics of program evaluation. Journal of Economic Literature 47(1), 5-86.

Jaksic, B. and G. Basic (2010) Roma settlements, living conditions and the possibility for integration of Roma in Serbia. Ethnicity Research Centre.

Janky, B. (2006) The social position and fertility of Roma women. In I. G. T. Ildikó Nagy and Marietta Pongrácz (eds.), Changing Roles: Report on the Situation of Women and Men in Hungary, pp. 132-145. Budapest: TÁRKI Social Research Institute.

Jayachandran, S. and R. Pande (2017) Why are Indian children so short? The role of birth order and son preference. The American Economic Review 107(9), 2600-2629.

Jensen, R. (2010) The (perceived) returns to education and the demand for schooling. Quarterly Journal of Economics 125(2), 515-548.

Jensen, R. (2012) Do labor market opportunities affect young women's work and family decisions? Experimental evidence from India. Quarterly Journal of Economics 127(2), 753-792.

Jurajda, S. and D. Kovač (2016) What's in a name in a war. Technical report.

Kalemli-Ozcan, S. (2002) Does the mortality decline promote economic growth? Journal of Economic Growth 7(4), 411-439.

Kaufmann, K. M. and O. Attanasio (2014) Educational choices and returns to schooling: mothers' and youths' subjective expectations and their role by gender. Journal of Development Economics 109(C), 201-216.

Kertesi, G. and G. Kézdi (2011a) Roma employment in Hungary after the post-communist transition. Economics of Transition 19(3), 563-610.

Kertesi, G. and G. Kézdi (2011b) The Roma/non-Roma test score gap in Hungary. American Economic Review: Papers \& Proceedings 101(3), 519-525.

Kertesi, G. and G. Kézdi (2013) Ethnic segregation between Hungarian schools: long-run trends and geographic distribution. Hungarian Statistical Review 16, 18-45.

Klemp, M. and J. Weisdorf (2019) Fecundity, fertility and the formation of human capital. The Economic Journal 129(618), 925-960.

La Ferrara, E. and A. Mele (2006) Racial segregation and public school expenditure. Technical report.

$\mathrm{Li}, \mathrm{H}$. and J. Zhang (2007) Do high birth rates hamper economic growth? Review of Economics and Statistics 89(1), 110-117.

LSMS (2007) Statistical Office of the Republic of Serbia. Serbia living standards measurement survey 2007, Ref.SRB_2007_LSMS_v01_M.

Manley, D., M. van Ham and J. Doherty (2011) Social mixing as a cure for negative neighbourhood effects: evidence based policy or urban myth? In T. Butler, L. Lees and G. Bridge (eds.), Mixed Communities: Gentrification by Stealth. Bristol: Policy Press, pp. 1-17.

Manski, C. F. and J. Mayshar (2003) Private incentives and social interactions: fertility puzzles in Israel. Journal of the European Economic Association 1(1), 181-211.

MICS (2010) United Nations Children's Fund, Statistical Office of the Republic of Serbia. Serbia Multiple Indicator Cluster Survey (MICS) 2010, Ref. SRB_2010_MICS_v01_M.

Montenegro, C. E. and H. A. Patrinos (2013) Returns to schooling around the world. Technical report, Background paper for the World Development Report 2013.

Nguyen, T. (2008) Information, role models and perceived returns to education: experimental evidence from Madagascar. Ph.D. thesis, Massachusetts Institute of Technology.

Open Society Institute (2007) Equal access to quality education for Roma. Technical report, Open Society Foundation.

Poston, D. L., C.-F. Chang and H. Dan (2006) Fertility differences between the majority and minority nationality groups in China. Population Research and Policy Review 25(1), 67-101.

Rauh, C. (2018) Decomposing gaps between Roma and non-Roma in Romania. Journal of Demographic Economics 84(2), 209-229. 
Sedlecky, K. and M. Rašević (2015) Challenges in sexual and reproductive health of Roma people who live in settlements in Serbia. The European Journal of Contraception \& Reproductive Health Care 20(2), 101-109.

Simon, C. J. and R. Tamura (2009) Do higher rents discourage fertility? Evidence from US cities, 19402000. Regional Science and Urban Economics 39(1), 33-42.

Spéder, Z. and F. Kamarás (2008) Hungary: secular fertility decline with distinct period fluctuations. Demographic Research 19, 599-664.

Spolaore, E. and R. Wacziarg (2016) Fertility and modernity. Technical report.

Stichnoth, H. and M. Yeter (2016) Cultural influences on the fertility behavior of first- and second-generation immigrants. Journal of Demographic Economics 82(3), 281-314.

UNFPA (2012) Sex imbalances at birth: current trends, consequences and policy implications. Technical report, UNFPA Asia and the Pacific Regional Office.

Cite this article: Battaglia M, Chabé-Ferret B, Lebedinski L (2021). Segregation, fertility, and son preference: the case of the Roma in Serbia. Journal of Demographic Economics 87, 233-260. https:// doi.org/10.1017/dem.2020.8 